\title{
IMUII Medication Adherence Does Not Explain Black-White Differences in Cardiometabolic Risk Factor Control among Insured Patients with Diabetes
}

Jennifer Elston Lafata, PhD 1,2,14, Andrew J. Karter, PhD ${ }^{3}$, Patrick J. O'Connor, MD, MA, MPH 4 , Heather Morris, PhD ${ }^{5}$, Julie A. Schmittdiel, $P h D^{3}$, Scott Ratliff, $M S^{7}$, Katherine M. Newton, PhD ${ }^{6}$, Marsha A. Raebel, PharmD 7,8 , Ram D. Pathak, MD, FACE, FACP9, Abraham Thomas, MD, MPH ${ }^{10}$, Melissa G. Butler, PharmD, MPH, PhD ${ }^{11}$, Kristi Reynolds, $P h D, M P H^{12}$, Beth Waitzfelder, $P h D^{13}$, and John F. Steiner, MD, MPH'

${ }^{1}$ School of Medicine, Virginia Commonwealth University, Richmond, VA, USA; ${ }^{2}$ Henry Ford Health System, Detroit, MI, USA; ${ }^{3}$ Division of Research, Kaiser Permanente Northern California, Oakland, CA, USA; ${ }^{4}$ HealthPartners Institute for Education and Research, Minneapolis, MN, USA; 5 University of Florida, Gainesville, FL, USA; ${ }^{6}$ Group Health Research Institute, Seattle, WA, USA; ${ }^{7}$ Kaiser Permanente Colorado Institute for Health Research, Denver, CO, USA; ${ }^{8}$ University of Colorado Skaggs School of Pharmacy and Pharmaceutical Sciences, Aurora, CO, USA; ${ }^{9}$ Marshfield Clinic, Marshfield, WI, USA; ${ }^{10}$ Lutheran HealthCare, Brooklyn, NY, USA; ${ }^{11}$ Kaiser Permanente Georgia Center for Health Research-Southeast, Atlanta, GA, USA; ${ }^{12}$ Department of Research and Evaluation, Kaiser Permanente Southern California, Los Angeles, CA, USA; ${ }^{13}$ Kaiser Permanente Hawaii, Center for Health Research - Hawaii, Honolulu, HI, USA; ${ }^{14}$ Department of Social and Behavioral Health, Virginia Commonwealth University, Richmond, VA, USA.

BACKGROUND: Among patients with diabetes, racial differences in cardiometabolic risk factor control are common. The extent to which differences in medication adherence contribute to such disparities is not known. We examined whether medication adherence, controlling for treatment intensification, could explain differences in risk factor control between black and white patients with diabetes.

METHODS: We identified three cohorts of black and white patients treated with oral medications and who had poor risk factor control at baseline (2009): those with glycated hemoglobin $(\mathrm{HbAlc})>8 \%(n=37,873)$, low-density lipoprotein cholesterol (LDL-C) $>100 \mathrm{mg} / \mathrm{dl}(n=27,954)$, and systolic blood pressure (SBP) $>130 \mathrm{~mm} \mathrm{Hg}(n=63,641)$. Subjects included insured adults with diabetes who were receiving care in one of nine U.S. integrated health systems comprising the SUrveillance, PREvention, and ManagEment of Diabetes Mellitus (SUPREME-DM) consortium. Baseline and follow-up risk factor control, sociodemographic, and clinical characteristics were obtained from electronic health records. Pharmacydispensing data were used to estimate medication adherence (i.e., medication refill adherence [MRA]) and treatment intensification (i.e., dose increase or addition of new medication class) between baseline and follow-up. County-level income and educational attainment were estimated via geocoding. Logistic regression models were used to test the association between race and follow-up risk factor control. Models were specified with and without medication adherence to evaluate its role as a mediator.

RESULTS: We observed poorer medication adherence among black patients than white patients $(p<0.01)$ : $50.6 \%$ of blacks versus $39.7 \%$ of whites were not highly

Received February 17, 2015

Revised June 11, 2015

Accepted July 23, 2015

Published online August 18, 2015 adherent (i.e., MRA <80 \%) to HbAlc oral medication(s); $58.4 \%$ of blacks and $46.7 \%$ of whites were not highly adherent to lipid medication(s); and $33.4 \%$ of blacks and $23.7 \%$ of whites were not highly adherent to BP medication(s). Across all cardiometabolic risk factors, blacks were significantly less likely to achieve control $(p<0.01)$ : $41.5 \%$ of blacks and $45.8 \%$ of whites achieved HbAlc $<8 \% ; 52.6 \%$ of blacks and $60.8 \%$ of whites achieved LDL$\mathrm{C}<100$; and $45.7 \%$ of blacks and $53.6 \%$ of whites achieved SBP <130. Adjusting for medication adherence/treatment intensification did not alter these patterns or model fit statistics.

CONCLUSIONS: Medication adherence failed to explain observed racial differences in the achievement of HbAlc, LDL-C, and SBP control among insured patients with diabetes.

KEY WORDS: diabetes care; racial disparities; medication adherence; cardiometabolic risk factors.

J Gen Intern Med 31(2):188-95

DOI: $10.1007 / \mathrm{s} 11606-015-3486-0$

(C) Society of General Internal Medicine 2015

\section{INTRODUCTION}

Poor cardiometabolic risk factor control substantially increases the risk of diabetes-related morbidity and mortality. ${ }^{1,2}$ Despite the availability of effective medications, almost half of all Americans with diabetes fail to maintain evidence-based goals for glycated hemoglobin (HbA1c), low-density lipoprotein cholesterol (LDL-C), and systolic blood pressure (SBP)..$^{3-7}$ Furthermore, suboptimal control is often more prevalent among African Americans. ${ }^{1,2,8-20}$

Prior research has consistently found racial differences in medication adherence. ${ }^{21-24}$ The reasons underlying such differences are poorly understood, but are often thought to stem 
from differences in care access, care quality, and selfmanagement behaviors. ${ }^{18}$ As medication non-adherence is associated with poor cardiometabolic risk factor control among patients with diabetes, ${ }^{8-14}$ it has been suggested that differences in medication adherence may be responsible for subgroup differences in risk factor control among patients with diabetes. ${ }^{18}$ These conclusions, however, are drawn from crosssectional studies and from analyses that fail to consider treatment intensification.

Longitudinal studies that address both medication adherence and treatment intensification are needed to fully understand the contribution of differences in medication adherence to racial differences in cardiometabolic risk factor control among patients with diabetes. Using the large patient populations and extensive clinical data available within the SUrveillance, PREvention, and ManagEment of Diabetes Mellitus (SUPREME-DM) consortium, ${ }^{25}$ we describe the achievement of cardiometabolic risk factor control among insured black and white patients with diabetes and poor baseline risk factor control. We then examine the extent to which medication adherence, controlling for treatment intensification, may explain black-white differences in the subsequent achievement of cardiometabolic risk factor control among these insured patients.

\section{METHODS}

\section{Sample and Setting}

We identified insured black and white patients aged 18 years and older with diabetes who were receiving care from one of nine health care systems in the U.S. participating in the SUPREME-DM consortium: Group Health (Washington), Henry Ford Health System/Health Alliance Plan (Michigan), Marshfield Clinic (Wisconsin), and Kaiser Permanente regions in Colorado, Northern California, Southern California, Hawaii, Georgia, and the Northwest (Oregon and Washington). Patients were identified as having diabetes if they had two outpatient visits or one inpatient discharge with an associated diagnostic code for diabetes (i.e., ICD-9 250.xx) or they had at least one dispensing of any glucose-lowering medication (exclusive of metformin) within the two-year period ending December $31,2010 .^{25}$ To ensure adequate capture of pharmacy dispensing data, we included only those patients with continuous insurance coverage with a drug benefit between January 1, 2009, and December 31, 2010.

Patients with diabetes were retrospectively selected for inclusion in up to three cohorts of patients with poorly controlled baseline cardiometabolic risk factors: (1) poorly controlled HbA1c (>8\%), (2) poorly controlled LDLC (>100 mg/dL), and/or (3) poorly controlled SBP $(>130 \mathrm{~mm} \mathrm{Hg})$. For each of the cohorts, patients were eligible for inclusion if they had a test result reflective of poor baseline risk factor control and a follow-up test result in the 12- to 18-month period following their baseline test. They also needed to be an oral medication user, with two or more dispensings for a corresponding medication (i.e., any oral glucose-lowering agent in the Hb1c cohort, any lipid-lowering agent in the LDL-C cohort, and any antihypertensive agent in the SBP cohort) in the period between their baseline and follow-up tests. Patients with no follow-up test result or with fewer than two relevant oral medication dispensings were excluded. Cohort members therefore included insured patients with a follow-up test in 2010 for whom we were able to follow medication management between this test and a baseline test $12-18$ months earlier that reflected poor control (Fig. 1). All study sites either ceded oversight to the Kaiser Permanente Colorado Institutional Review Board (IRB) or received approval from their local IRB for the study.

\section{Data Sources}

Study data were compiled from the SUPREME-DM DataLink, ${ }^{13,25}$ a distributed data source of patients with diabetes derived from the HMO Research Network Virtual Data Warehouse (VDW). ${ }^{26,27}$ Within each delivery system, the VDW contains data from electronic health records (EHRs) joined with administrative data in identically formatted tables. Included in the VDW is information extracted from automated administrative and encounter files on patient sociodemographic characteristics and insurance coverage, dates and results of vital signs and laboratory testing, pharmacy dispensing, and dates and diagnoses associated with ambulatory visits and inpatient stays. While each delivery system maintains their own VDW database, its use enables the distribution of standardized analyses programs for site-level database construction. Uniform sitelevel databases are transferred and joined for analyses.

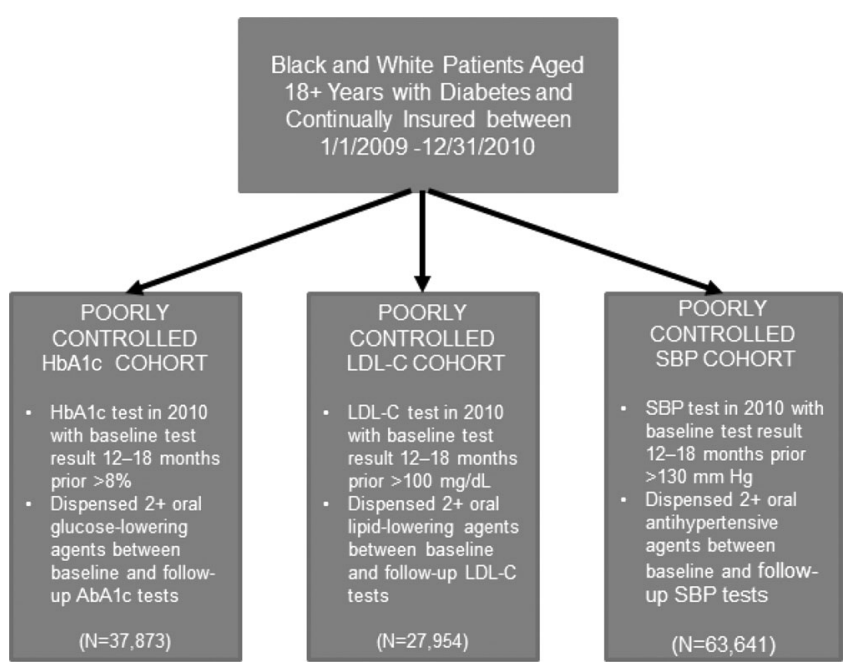

Figure 1. Study cohorts. 


\section{Analytical Variables}

The primary outcome of interest was whether the patient achieved the guideline-defined threshold for control at follow-up (i.e., "goal attainment"), consistent with practice standards during the period of observation (i.e., $\mathrm{HbA} 1 \mathrm{c}<8 \%$, LDL-C $<100 \mathrm{mg} / \mathrm{dl}$, and $\mathrm{SBP}<130 \mathrm{~mm} \mathrm{Hg}){ }^{28}$ As a secondary outcome, we also evaluated whether the patient had achieved a clinically substantive improvement in control at follow-up (i.e., "improvement"). For the HbAlc cohort, this was defined as a reduction in $\mathrm{HbAlc} \geq 1 \%{ }^{29}$ For the LDL cohort, we used a reduction in LDL-C of $\geq 10 \%,{ }^{30}$ and for the SBP cohort we used a reduction in $\mathrm{SBP} \geq 5.5 \mathrm{~mm} \mathrm{Hg} .{ }^{31}$

Medication adherence was calculated for oral glucoselowering medications, antihypertensives, and lipid-lowering agents within the HbAlc, SBP, and LDL-C cohorts, respectively, and was measured using dispensing data from the 12month period immediately preceding the patient's follow-up test date. We estimated a continuous multiple-interval measure of medication refill adherence (MRA) $)^{32,33}$ as the days' supply dispensed during the 12-month period divided by the number of days of observation with evidence of a dispensing. For patients taking medications from more than one medication class simultaneously for a given indication, we used the average MRA across those classes to obtain an overall measure of adherence to oral medications. Patients with MRA $\geq 80 \%$ were classified as "adherent" ${ }^{34}$ Among patients who were adherent in the follow-up period, we controlled for whether their treatment was intensified during follow-up. Treatment intensification was defined as any dispensing of a new class of relevant medications (including insulin) or a dose increase within the same class of medications, using dispensing data from the period between baseline and follow-up test dates. ${ }^{35}$

Inpatient and outpatient diagnostic codes from the same period were used to construct the Deyo adaptation of the Charlson Comorbidity Index. ${ }^{36}$ Similarly, diabetes-related comorbidities and complications including cardiovascular disease (CVD), end-stage renal disease (ESRD), retinopathy, and amputation were identified based on ICD-9 diagnosis and procedure codes. Also available from the EHR were age, gender, race, and body mass index (BMI). Race, regardless of health care system, is almost always based on self-reported information, and was extracted from the EHR to the VDW (and thus DataLink) in accordance with the categories included in the National Institutes of Health policy and guidelines on including women and minorities as subjects in clinical research. ${ }^{37}$ Contextual socioeconomic status (SES) indicators were obtained from geocoded information on residential street address and 2000 U.S. Census-reported county-level median household income and educational attainment. ${ }^{13}$

\section{Statistical Analysis}

Within each cohort, we calculated the percentage of patients who were non-adherent to their medications during the followup period and the percentage of patients who were adherent without a corresponding treatment intensification as well as the percentage who were adherent with a treatment intensification following their baseline test result. We calculated the percentage of patients within each cohort who (1) had achieved risk factor control (i.e., "goal attainment") at the end of the follow-up period (as defined by the guidelinedefined threshold value) and (2) had attained a clinically substantive improvement in control by the end of the followup period. Unadjusted differences in the proportion of patients with goal attainment and improvement by race were assessed with chi-square tests, as were differences in adherence/ intensification status by race. Adjusted differences in the proportion of patients achieving control and attaining a substantive improvement were evaluated using logistic regression. Models were fitted in two steps. In the base model, the dependent variable (i.e., control or improvement) was modeled as a function of race, controlling for the patient's age, income, gender, insulin use, Charlson comorbidity score, level of the corresponding risk factor at baseline, BMI, frequency of visits to primary care, whether they were seen in endocrinology, the presence/absence of CVD, ESRD, retinopathy, or amputation, and a fixed effect for delivery system. Then, to test our hypothesis that medication adherence, controlling for treatment intensification, explains black-white differences in risk factor outcomes, we added the hypothesized mediator, i.e., patient's medication adherence/intensification status, to the base model. The sensitivity of model results to the inclusion of a continuous measure of MRA was also assessed. All analyses were conducted using SAS version 9.4 software (SAS Institute Inc., Cary, NC).

\section{RESULTS}

\section{Sample Characteristics}

We identified insured adults who were eligible for inclusion in the HbA1c $(N=37,873)$, LDL-C $(N=27,954)$, and SBP $(N=63,641)$ risk cohorts. By cohort inclusion criteria, at baseline, all individuals included in each cohort were in poor control for the corresponding risk factor. While almost half of the members of the SBP cohort were over the age of 64 , just under a third of the LDL-C cohort and approximately a quarter of the HbA1c cohort were over age 64 (Table 1). Approximately $20 \%$ of each cohort comprised blacks, and approximately half of each were women, while approximately two-thirds of each cohort resided in communities where the median household income ranged from $\$ 30,000$ to $\$ 69,999$. At baseline, the median $\mathrm{HbA} 1 \mathrm{c}$ was $9.2 \%$ for black patients compared to $9.0 \%$ for white patients in the $\mathrm{HbA} 1 \mathrm{C}$ cohort; the median LDL-C was $123 \mathrm{mg} / \mathrm{dL}$ for black patients and $119 \mathrm{mg} / \mathrm{dL}$ for white patients in the LDL-C cohort; and median SBP was $142 \mathrm{~mm} \mathrm{Hg}$ for black patients and $140 \mathrm{~mm} \mathrm{Hg}$ for white patients in the SBP cohort (Table 1). 
Table 1 Baseline Patient Sociodemographic and Health-Related Characteristics by Cardiometabolic Risk Factor Cohort and Race

\begin{tabular}{|c|c|c|c|c|c|c|}
\hline & \multicolumn{6}{|l|}{ Cohort } \\
\hline & \multicolumn{2}{|l|}{ HbA1c } & \multicolumn{2}{|l|}{ LDL-C } & \multicolumn{2}{|l|}{ SBP } \\
\hline & $\begin{array}{l}\text { Black } \\
N=7893\end{array}$ & $\begin{array}{l}\text { White } \\
N=29,980\end{array}$ & $\begin{array}{l}\text { Black } \\
N=5872\end{array}$ & $\begin{array}{l}\text { White } \\
N=22,082\end{array}$ & $\begin{array}{l}\text { Black } \\
N=12,831\end{array}$ & $\begin{array}{l}\text { White } \\
N=50,810\end{array}$ \\
\hline \multicolumn{7}{|l|}{ Sociodemographic characteristics } \\
\hline Age $(\%)$ & & * & & $*$ & & * \\
\hline $18-49$ years & 25.7 & 21.7 & 21.7 & 17.9 & 14.5 & 9.5 \\
\hline $50-64$ years & 49.0 & 48.0 & 45.7 & 45.7 & 42.0 & 37.9 \\
\hline $65-74$ years & 18.2 & 20.7 & 23.7 & 23.8 & 28.4 & 30.3 \\
\hline$\geq 75$ years & 7.1 & 9.6 & 8.8 & 12.6 & 15.1 & 22.3 \\
\hline Female (\%) & 52.2 & $45.6^{*}$ & 58.7 & $53.4 *$ & 58.8 & $50.1^{*}$ \\
\hline Geocoded income (\%) & & * & & $*$ & & \\
\hline$\leq \$ 29,999$ & 14.4 & 6.6 & 13.0 & 6.1 & 14.9 & 5.9 \\
\hline$\$ 30,000-\$ 69,999$ & 67.2 & 65.0 & 67.2 & 62.5 & 66.7 & 63.4 \\
\hline$\geq \$ 70,000$ & 18.5 & 28.4 & 19.8 & 31.5 & 18.3 & 30.7 \\
\hline \multicolumn{7}{|l|}{ Health-related characteristics } \\
\hline Median (IQR) Charlson index & $\begin{array}{l}3.0 \\
(1.0-5.0)\end{array}$ & $\begin{array}{l}3.0 \\
(1.0-5.0)\end{array}$ & $\begin{array}{l}2.0 \\
(1.0-5.0)\end{array}$ & $\begin{array}{l}2.0^{\dagger} \\
(1.0-4.0)\end{array}$ & $\begin{array}{l}3.0 \\
(1.0-5.0)\end{array}$ & $\begin{array}{l}3.0^{\dagger} \\
(1.0-5.0)\end{array}$ \\
\hline Dispensed insulin (\%) & 46.1 & 46.7 & 22.6 & 21.8 & 25.5 & 25.1 \\
\hline \multicolumn{7}{|l|}{ Complications (\%) } \\
\hline CVD & 5.2 & 5.3 & 6.2 & 6.4 & 7.1 & $8.9^{*}$ \\
\hline ESRD & 1.0 & 0.9 & 1.2 & $0.9 * *$ & 2.0 & $1.6^{*}$ \\
\hline Retinopathy & 3.4 & 3.3 & 2.5 & 2.1 & 4.1 & 3.8 \\
\hline Amputation & 1.7 & 1.7 & 1.3 & $1.0 * *$ & 1.8 & 1.8 \\
\hline Mean (SD) BMI & $34.2(7.5)$ & $34.2(7.4)$ & $33.6(7.4)$ & $33.3(7.1)^{\ddagger}$ & $33.8(7.7)$ & $33.6(7.6)^{\ddagger}$ \\
\hline Median number of PC visits (IQR) & $\begin{array}{l}5.0 \\
(3.0-9.0)\end{array}$ & $\begin{array}{l}5.0^{\dagger} \\
(2.0-8.0)\end{array}$ & $\begin{array}{l}5.0 \\
(3.0-9.0)\end{array}$ & $\begin{array}{l}5.0^{\dagger} \\
(2.0-8.0)\end{array}$ & $\begin{array}{l}6.0 \\
(4.0-10.0)\end{array}$ & $\begin{array}{l}6.0^{\dagger} \\
(3.0-10.0)\end{array}$ \\
\hline Seen by endocrinology $(\%)$ & 12.4 & $10.9^{*}$ & 10.3 & $8.8^{*}$ & 9.6 & $8.0^{*}$ \\
\hline Median baseline test result (IQR) & $\begin{array}{l}9.2 \% \\
(8.5-10.4)\end{array}$ & $\begin{array}{l}9.0 \%^{\dagger} \\
(8.4-10.0)\end{array}$ & $\begin{array}{l}123 \mathrm{mg} / \mathrm{dL} \\
(109-146)\end{array}$ & $\begin{array}{l}119 \mathrm{mg} / \mathrm{dL}^{\dagger} \\
(108-138)\end{array}$ & $\begin{array}{l}142 \mathrm{~mm} \mathrm{Hg} \\
(136-152)\end{array}$ & $\begin{array}{l}140 \mathrm{~mm} \mathrm{Hg} \\
(135-150)\end{array}$ \\
\hline
\end{tabular}

HbAlc hemoglobin A1c, LDL-C low-density lipoprotein cholesterol, SBP systolic blood pressure, CVD cardiovascular disease, ESRD end-stage renal disease, BMI body mass index, PCP primary care, IQR interquartile range

Statistical methods used to test sociodemographic and other differences by race within each cohort:

* Chi-square test $p<0.01$

$* *$ Chi-square test $p<0.05$

"Wilcoxon rank-sum test $p<0.001$

${ }^{*}$ Student $t$ test $p<0.01$

\section{Medication Adherence During Follow-Up}

During the follow-up period, $42.0 \%$ of the HbAlc cohort and $49.1 \%$ of the LDL-C cohort were non-adherent to their medications, compared to $25.7 \%$ of the SBP cohort (Table 2). Among adherent patients, between $14.5 \%$ (HbAlc cohort) and $26.2 \%$ (LDL-C cohort) received a treatment intensification during the follow-up period, and between $24.7 \%$ (LDL-C cohort) and $50.4 \%$ (SBP cohort) received no treatment intensification. Regardless of cohort, black patients were always significantly more likely than white patients to be non-adherent during the follow-up period, and less likely to be adherent without a treatment intensification during follow-up.

\section{Follow-Up Cardiometabolic Risk Factor Status}

At follow-up, $44.9 \%$ of the HbA1c cohort had achieved HbAlc control (i.e., HbAlc $<8 \%$ ) and $49.3 \%$ had a clinically meaningful improvement (i.e., at least one-percentage-point reduction). In the SBP cohort, $52.0 \%$ achieved control (SBP $<130 \mathrm{~mm} \mathrm{Hg}$ ), while $68.7 \%$ had a clinically meaningful improvement (reduction of $5.5 \mathrm{~mm} \mathrm{Hg}$ or more). In the

Table 2 Percentage of Patients by Medication Adherence Status During Follow-Up, Cardiometabolic Risk Factor Cohort and Race

\begin{tabular}{|c|c|c|c|c|c|c|c|c|c|}
\hline \multirow[t]{3}{*}{ Adherence status } & \multicolumn{9}{|l|}{ Cohort } \\
\hline & \multicolumn{3}{|l|}{ HbA1C* } & \multicolumn{3}{|l|}{ LDL-C* } & \multicolumn{3}{|l|}{ SBP* } \\
\hline & $\begin{array}{l}\text { All } \\
N=37,873\end{array}$ & $\begin{array}{l}\text { Black } \\
N=7893\end{array}$ & $\begin{array}{l}\text { White } \\
N=29,980\end{array}$ & $\begin{array}{l}\text { All } \\
N=27,954\end{array}$ & $\begin{array}{l}\text { Black } \\
N=5872\end{array}$ & $\begin{array}{l}\text { White } \\
N=22,082\end{array}$ & $\begin{array}{l}\text { All } \\
N=63,641\end{array}$ & $\begin{array}{l}\text { Black } \\
N=12,831\end{array}$ & $\begin{array}{l}\text { White } \\
N=\mathbf{5 0 , 8 1 0}\end{array}$ \\
\hline $\begin{array}{l}\text { Non-adherent } \\
\text { Adherent }\end{array}$ & 42.0 & 50.6 & 39.7 & 49.1 & 58.4 & 46.7 & 25.7 & 33.4 & 23.7 \\
\hline $\begin{array}{l}\text { With intensification } \\
\text { Without intensification }\end{array}$ & $\begin{array}{l}14.5 \\
43.6\end{array}$ & $\begin{array}{l}13.8 \\
35.7\end{array}$ & $\begin{array}{l}14.7 \\
45.6\end{array}$ & $\begin{array}{l}26.2 \\
24.7\end{array}$ & $\begin{array}{l}23.7 \\
17.9\end{array}$ & $\begin{array}{l}26.8 \\
26.5\end{array}$ & $\begin{array}{l}24.0 \\
50.4\end{array}$ & $\begin{array}{l}23.4 \\
43.2\end{array}$ & $\begin{array}{l}24.1 \\
52.2\end{array}$ \\
\hline
\end{tabular}

HbAlc hemoglobin Alc, LDL-C low-density lipoprotein cholesterol, SBP systolic blood pressure

*Chi-square test $p<0.0001$ 
LDL-C cohort, $59.1 \%$ achieved LDL-C control (LDL-C $<100 \mathrm{mg} / \mathrm{dL}$ ), and $70.0 \%$ had a clinically meaningful improvement (reduction of $10 \%$ or more).

Before controlling for other factors, regardless of cohort, black patients were significantly less likely than white patients to achieve control (Table 3). This was true regardless of their medication adherence status. Similarly, black patients were significantly less likely than white patients to have a clinically beneficial improvement in either LDL-C or SBP level, regardless of their medication adherence status (Table 3). Differences in clinically beneficial HbAlc improvements were similar, albeit less pronounced.

Results from adjusted models confirmed these findings (Table 4). Regardless of cohort, compared to white patients, black patients in all models were significantly less likely to achieve control or a clinically meaningful improvement. These race differences persisted in models that controlled for the patient's medication adherence status, altering neither observed relationship patterns nor model fit statistics substantively (differences in c-statistics ranged from 0.003 to 0.015). Results and findings did not differ substantively with the inclusion of a continuous measure of MRA (results not shown).

\section{DISCUSSION}

Our findings highlight persistent black-white differences in both medication adherence and the attainment of optimal cardiometabolic risk factor control among patients with diabetes. Among large populations of insured patients receiving care from integrated delivery systems located across the
United States, we found that black patients experiencing suboptimal risk factor control at baseline were less likely than white patients to adhere to medications during follow-up, and were subsequently less likely to achieve recommended goal levels for HbA1c, LDL-C, or SBP, even when their medication was intensified. While medication adherence status was significantly associated with achieving recommended goal levels, it did not fully explain observed racial disparities in the control of cardiometabolic risk factors among patients with diabetes.

Both medication adherence and treatment intensification are advocated for controlling cardiometabolic risk factors among patients with diabetes. ${ }^{38}$ While findings continually point to delays in treatment intensification, ${ }^{39-43}$ findings of differences in delay length by race have been inconsistent. ${ }^{39-43}$ On the other hand, studies of medication adherence have consistently found black patients to be less adherent to prescribed medications. $^{22-24}$ Our understanding of the impact of medication adherence and treatment intensification to observed racial differences in risk factor control among patients with diabetes remains limited. This is especially true as few prior studies have considered the joint effects of medication adherence and treatment intensification on risk factor control among patients with diabetes. One study that has done so did not explore differences by patient race. ${ }^{44}$

The complex mix of patient, physician, and system factors associated with both medication adherence ${ }^{45-47}$ and treatment intensification ${ }^{42,48-50}$ has been well documented, as have the ongoing challenges in achieving clinical control even when patients are adherent and treatment is intensified. ${ }^{44,51,52}$ It is therefore encouraging to see that within a relatively short follow-up period, a substantial percentage of patients who were in poor control at baseline were able to achieve

Table 3 Percentage of Patients with Goal Attainment and Improvement at Follow-Up by Risk Factor Cohort, Race and Medication Adherence Status

\begin{tabular}{|c|c|c|c|c|c|c|c|c|c|}
\hline \multirow[t]{4}{*}{ Adherence status } & \multicolumn{9}{|l|}{ Cohort } \\
\hline & \multicolumn{3}{|l|}{ HbA1C } & \multicolumn{3}{|l|}{ LDL-C } & \multicolumn{3}{|l|}{ SBP } \\
\hline & \multicolumn{3}{|l|}{ Race } & \multicolumn{3}{|l|}{ Race } & \multicolumn{3}{|l|}{ Race } \\
\hline & $\begin{array}{l}\text { All } \\
N=37,873\end{array}$ & $\begin{array}{l}\text { Black } \\
N=7893\end{array}$ & $\begin{array}{l}\text { White } \\
N=29,980\end{array}$ & $\begin{array}{l}\text { All } \\
N=27,954\end{array}$ & $\begin{array}{l}\text { Black } \\
N=5872\end{array}$ & $\begin{array}{l}\text { White } \\
N=22,082\end{array}$ & $\begin{array}{l}\text { All } \\
N=63,641\end{array}$ & $\begin{array}{l}\text { Black } \\
N=12,831\end{array}$ & $\begin{array}{l}\text { White } \\
N=\mathbf{5 0 , 8 1 0}\end{array}$ \\
\hline \multicolumn{10}{|l|}{ Goal attainment } \\
\hline Non-adherent & 38.7 & 37.0 & $39.2 * *$ & 52.3 & 47.1 & $54.0 *$ & 48.3 & 41.8 & $50.5^{*}$ \\
\hline Adherent & 49.5 & 43.6 & $50.9^{*}$ & 63.1 & 57.0 & $64.5^{*}$ & 50.1 & 45.3 & $51.2 *$ \\
\hline \multicolumn{10}{|l|}{ w/intensification } \\
\hline Adherent w/o intensification & 49.4 & 46.9 & $49.9^{*}$ & 68.3 & 64.7 & $68.9 *$ & 54.8 & 49.0 & $56.1 *$ \\
\hline All & 44.9 & 41.5 & $45.8^{*}$ & 59.1 & 52.6 & $60.8 *$ & 52.0 & 45.7 & $53.6^{*}$ \\
\hline \multicolumn{10}{|l|}{ Improvement } \\
\hline Non-adherent & 46.8 & 48.1 & 46.4 & 66.0 & 63.5 & $66.8^{*}$ & 66.5 & 62.6 & $67.9^{*}$ \\
\hline Adherent w/ & 54.4 & 51.1 & $55.3 * *$ & 74.3 & 70.6 & $75.2 *$ & 68.0 & 65.1 & $68.7 *$ \\
\hline \multicolumn{10}{|l|}{ intensification } \\
\hline Adherent w/o intensification & 50.0 & 49.5 & 50.1 & 73.3 & 70.7 & $73.7 * *$ & 70.2 & 66.2 & $71.0^{*}$ \\
\hline All & 49.3 & 49.0 & 49.4 & 70.0 & 66.5 & $70.9 *$ & 68.7 & 64.7 & $69.7 *$ \\
\hline
\end{tabular}

Where $\mathrm{HbAlc}<8 \%, L D L<100 \mathrm{mg} / \mathrm{dL}$, and systolic $\mathrm{BP}<130 \mathrm{~mm} \mathrm{Hg}$ defined as achieving control

Where $H b A l c$ reduction $\geq 1 \%$, LDL-C reduction $\geq 10 \%$, and $S B P$ reduction $\geq 5.5 \mathrm{~mm} \mathrm{Hg}$

HbAlc hemoglobin Alc, LDL-C low-density lipoprotein cholesterol, SBP systolic blood pressure

$*$ Chi-square test $p<0.01$

$* *$ Chi-square test $p<0.05$ 
Table 4 Adjusted Logistic Regression Results for Race and Follow-Up Goal Attainment and Improvement by Risk Factor: Base Models and Models with Medication Adherence Status

\begin{tabular}{|c|c|c|c|c|c|c|}
\hline & \multicolumn{2}{|l|}{ HbA1c } & \multicolumn{2}{|l|}{ LDL-C } & \multicolumn{2}{|l|}{ SBP } \\
\hline & Base model & Model w/adherence & Base model & Model w/adherence & Base model & Model w/adherence \\
\hline & OR (95 \% CI) & OR (95\% CI) & OR (95 \% CI) & OR (95\% CI) & OR (95\% CI) & OR $(95 \%$ CI) \\
\hline \multicolumn{7}{|c|}{ Goal attainment } \\
\hline Race & & $\ddagger$ & * & $*$ & * & * \\
\hline White & 1.00 & 1.00 & 1.00 & 1.00 & 1.00 & 1.00 \\
\hline Black & $0.91(0.86-0.97)$ & $0.94(0.89-0.99)$ & $0.79(0.75-0.85)$ & $0.82(0.77-0.88)$ & $0.77(0.74-0.80)$ & $0.78(0.75-0.82)$ \\
\hline C statistic & 0.64 & 0.65 & 0.63 & 0.64 & 0.61 & 0.61 \\
\hline $\begin{array}{l}\text { Improvement } \\
\text { Race }\end{array}$ & * & * & * & * & $*$ & $*$ \\
\hline White & 1.00 & 1.00 & 1.00 & 1.00 & 1.00 & 1.00 \\
\hline Black & $0.88(0.84-0.94)$ & $0.91(0.85-0.96)$ & $0.79(0.73-0.84)$ & $0.81(0.76-0.87)$ & $0.76(0.73-0.80)$ & $0.77(0.74-0.81)$ \\
\hline C statistic & 0.70 & 0.70 & 0.62 & 0.63 & 0.69 & 0.69 \\
\hline
\end{tabular}

Base models control for age, gender, income, Charlson Comorbidity Index, insulin dispensing, cardiovascular disease, end-stage renal disease, retinopathy, amputation, BMI, baseline risk factor level, number of visits to primary care during follow-up, whether the patient was seen in endocrinology during follow-up, and health care system. Models with adherence control for these factors plus medication adherence status in three categories: non-adherent; adherent with intensification; adherent without intensification

$* p<0.001$

$t_{p} p 0.01$

${ }^{t} p<0.05$

recommended control levels. This finding was consistent across each of the cardiometabolic risk factors, albeit notably less so for $\mathrm{HbA} 1 \mathrm{c}$ goal attainment. Furthermore, we found that even larger percentages of those in poor control at baseline achieved clinically beneficial improvements in control, even if these improvements did not always reach guidelinerecommended thresholds. Such positive findings are consistent with recent national and international trends in $\mathrm{HbAlc}$, SBP, and LDL-C control. ${ }^{53-55}$

Our finding that black patients are less likely to achieve recommended risk factor control even after considering medication adherence and treatment intensification emphasize the difficulty of overcoming such disparities and the likely complex pathways through which race may impact the achievement of clinically advocated treatment goals. Our understanding of these complex pathways remains incomplete. Some of these pathways could include race differences in individuallevel socioeconomic status, functional health literacy, and the quality of patient-physician communication. They may also be related to the overall cultural competency of clinicians and staff in the environment in which care is received. Stress - be it at an individual, family, or community level—may further contribute to observed racial disparities in adherence and clinical control. Interventions addressing a complex array of biological, physiologic, and behavioral factors are likely needed to effectively address disparities. Given that previous studies have shown that racial disparities persist in both care processes and risk factor control, even within an environment where the overall quality of care is improving, ${ }^{53}$ it is likely that interventions specifically tailored to African Americans are needed to reduce disparities in CVD risk factor control. When desired treatment goals in patients with diabetes are not met, the American Diabetes Association now advocates for the evaluation of a diverse collection of patient barriers such as financial barriers, health literacy, diabetes-related distress, or depression, and provider barriers such as competing clinical demands. ${ }^{56}$ To fully address racial disparities, additional potential barriers at the health care system, community, and policy level also merit consideration. ${ }^{57,58}$

Several limitations of our study should be noted. First, our method of ascertaining adherence excludes patients who obtained less than two dispensings of a medication; thus we are unable to identify non-adherent patients in cases where medications were prescribed but never dispensed or where a new medication was only dispensed a single time. This could result in biases if African American patients are relatively less likely than white patients to fill only one prescription for a medication. This also implies a slight under-ascertainment of intensification, given that $\sim 5 \%$ of patients prescribed a new medication (i.e., the provider's plan was for intensification) are never dispensed the newly prescribed medication. ${ }^{14,59,60} \mathrm{Sec}-$ ond, we measured medication dispensing, not actual consumption or prescribing. As such, our measure of adherence may be inflated, and our measure of treatment intensification will miss prescriptions written but never filled. Furthermore, our measure of secondary medication adherence ignored adherence to prescribed insulin and gaps or stockpiling across refill intervals, and thus we assume that their impact is uniform across groups. Similarly, measures of treatment intensification derived from electronic dispensing data (such as the one used here) have not been formally validated and may have shortcomings. For example, alterations in insulin dosing or changes in dose that are achieved via an increase in the quantity of pills taken are not identifiable via dispensing data. Nor can the rationale behind observed intensifications be ascertained. Thus, changes due to insurance coverage or other nonclinical factors are captured equally to those driven by clinical factors. Our results may not generalize to other practice sites or patient populations. In particular, while both privately and 
publicly insured individuals were included, patients without insurance were excluded. Furthermore, because analyses were limited to data available via automated sources, we were unable to consider other factors that may influence medication management and the achievement of control, including patient-provider relationship factors, patient health beliefs, preferences, and individual level income/socioeconomic status, or broad system-level initiatives to achieve quality targets for risk factor control. Strengths of our study include the use of longitudinal data from geographically diverse health systems, findings regarding adherence and cardiometabolic control that are consistent with previous studies, and the ability to jointly control for medication adherence and intensification.

In summary, the results of this study highlight the need to look at factors beyond the joint effects of medication adherence and treatment intensification in order to understand the root causes of observed black-white differences in $\mathrm{HbA1c}$, LDL-C, and SBP control among patients with diabetes. These factors may range from biological mechanisms that alter drug effectiveness, to physiologic factors such as genetics, known race differences in the viability of risk factor control markers (e.g., race differences in glycosylation of hemoglobin), ${ }^{61}$ to other patient, provider, and health system factors that may influence health behaviors, treatment decisions, and health outcomes.

\begin{abstract}
Acknowledgments: We gratefully acknowledge the work of the project managers at KPCO, Andrea Paolino, MA, and Michael Shainline, MS, MBA. We thank the programmers and site investigators at Kaiser Permanente Colorado, Northwest, Northern California, Southern California, Georgia and Hawaii, Geisinger Health System, Marshfield Clinic Research Foundation, Henry Ford Health System, and Group Health Research Institute for their efforts in developing and refining the SUPREME-DM datasets that informed this work.
\end{abstract}

Funders: This project was supported by grant number R01HS019859 from the Agency for Healthcare Research and Quality.

\section{Prior Presentations: EDEG, April 2015, Chantilly, France.}

Conflict of interest: The authors declare that they do not have a conflict of interest.

Corresponding Author: Jennifer Elston Lafata, PhD; Department of Social and Behavioral HealthVirginia Commonwealth University, PO Box 980149, Richmond, VA 23298, USA (e-mail: jelstonlafat@vcu.edu).

\section{REFERENCES}

1. Gaede $\mathbf{P}$, et al. Multifactorial intervention and cardiovascular disease in patients with type 2 diabetes. N Engl J Med. 2003;348(5):383-393.

2. Gaede $\mathbf{P}$, et al. Effect of a multifactorial intervention on mortality in type 2 diabetes. N Engl J Med. 2008;358(6):580-591.

3. Casagrande SS, et al. The prevalence of meeting A1C, blood pressure, and LDL goals among people with diabetes, 1988-2010. Diabetes Care. 2013;36(8):2271-2279.

4. Ali MK, Bullard KM, Gregg EW. Achievement of goals in U.S. Diabetes Care, 1999-2010. N Engl J Med. 2013;369(3):287-288.

5. Nathan DM, et al. Medical management of hyperglycemia in type 2 diabetes: a consensus algorithm for the initiation and adjustment of therapy a consensus statement of the American Diabetes Association and the European Association for the Study of Diabetes. Diabetes Care. 2009;32(1): 193-203.

6. Aguilar M, et al. A desktop guide to type 2 diabetes mellitus. Diabet Med. 1999; 16(9):716-730.

7. American Diabetes Association. Standards of medical care in diabetes-2008. Diabetes Care. 2008;31 (Suppl 1):S12-54.

8. Phillips LS, et al. An endocrinologist-supported intervention aimed at providers improves diabetes management in a primary care site improving primary care of African Americans with diabetes (IPCAAD) 7. Diabetes Care. 2005;28(10):2352-2360.

9. Grant RW, Buse JB, Meigs JB. Quality of diabetes care in US Academic Medical Centers low rates of medical regimen change. Diabetes Care. 2005;28(2):337-442.

10. Shah BR, et al. Clinical inertia in response to inadequate glycemic control do specialists differ from primary care physicians? Diabetes Care. 2005;28(3):600-606.

11. Rodondi $\mathbf{N}$, et al. Therapy modifications in response to poorly controlled hypertension, dyslipidemia, and diabetes mellitus. Ann Intern Med. 2006; 144(7):475-484.

12. Berlowitz DR, et al. Developing a quality measure for clinical inertia in diabetes care. Health Serv Res. 2005;40(6p1):1836-1853.

13. Schmittdiel JA, Uratsu CS, Karter AJ, Heisler M, Subramanian U, Mangione CM, et al. Poor adherence versus lack of treatment intensification? Poor adherence versus lack of treatment intensification. J Gen Intern Med. 2008;23(5):588-594.

14. Karter AJ, et al. New prescription medication gaps: a comprehensive measure of adherence to new prescriptions. Health Serv Res. 2009;44(5 Pt 1):1640-1661.

15. Rehman SU, et al. Ethnic differences in blood pressure control among men at Veterans Affairs clinics and other health care sites. Arch Intern Med. 2005;165(9): 1041-1047.

16. Bosworth HB, et al. Racial differences in blood pressure control: potential explanatory factors. Am J Med. 2006;119(1):70 e9-70 e15.

17. Trivedi AN, et al. Despite improved quality of care in the Veterans Affairs health system, racial disparity persists for important clinical outcomes. Health Aff (Millwood). 2011;30(4):707-715.

18. Heisler M, et al. Mechanisms for racial and ethnic disparities in glycemic control in middle-aged and older Americans in the health and retirement study. Arch Intern Med. 2007;167(17):1853-1860.

19. Heisler M, et al. Racial disparities in diabetes care processes, outcomes, and treatment intensity. Med Care. 2003;41(11):1221-1232.

20. Kirk JK, et al. Disparities in HbAlc levels between African-American and non-Hispanic white adults with diabetes: a meta-analysis. Diabetes Care. 2006;29(9):2130-2136.

21. Krousel-Wood MA, et al. Barriers to and determinants of medication adherence in hypertension management: perspective of the cohort study of medication adherence among older adults. Med Clin North Am. 2009;93(3):753-769.

22. Kulik A, et al. Adherence to statin therapy in elderly patients after hospitalization for coronary revascularization. Am J Cardiol. 2011;107(10):1409-1414.

23. Trinacty $\mathbf{C M}$, et al. Racial differences in long-term adherence to oral antidiabetic drug therapy: a longitudinal cohort study. BMC Health Serv Res. 2009;9:24.

24. Tseng CW, et al. Race/ethnicity and economic differences in cost-related medication underuse among insured adults with diabetes: the Translating Research Into Action for Diabetes Study. Diabetes Care. 2008;31(2):261-266.

25. Nichols GA, et al. Construction of a multisite DataLink using electronic health records for the identification, surveillance, prevention, and management of diabetes mellitus: the SUPREME-DM project. Prev Chronic Dis. 2012;9:E110.

26. National Cancer Institute. The HMO CRN: Cancer Research Network. 7/24/2013]; Available from: http://crn.cancer.gov/; accessed 7/22/15.

27. Ross TR, Ng D, Brown JS, Pardee R, Hornbrook MC, Hart G, Steiner JF. The HMO research network virtual data warehouse: a public data model to support collaboration. eGEMs (Generating Evidence \& Methods to improve patient outcomes). 2014;2(1): 1049.

28. American Diabetes Association. Professional practice committee for the standards of medical care in diabetes-2015. Diabetes Care. 2015;38(Supplement 1):S88-S89.

29. The Diabetes Control and Complications Trial Research Group. The effect of intensive treatment of diabetes on the development and progression of long-term complications in insulin-dependent diabetes mellitus. N Engl J Med. 1993;329(14):977-86.

30. Law MR, Wald NJ, Thompson SG. By how much and how quickly does reduction in serum cholesterol concentration lower risk of ischaemic heart disease? BMJ. 1994;308(6925):367-372. 
31. Harsha DW, Bray GA. Weight loss and blood pressure control (Pro). Hypertension. 2008;51(6): 1420-1425. discussion 1425.

32. Steiner JF, Prochazka AV. The assessment of refill compliance using pharmacy records: methods, validity, and applications. J Clin Epidemiol. 1997;50(1):105-116.

33. Hess LM, et al. Measurement of adherence in pharmacy administrative databases: a proposal for standard definitions and preferred measures. Ann Pharmacother. 2006;40(7-8):1280-1288.

34. Ho PM, Bryson CL, Rumsfeld JS. Medication adherence: its importance in cardiovascular outcomes. Circulation. 2009;119(23):3028-3035.

35. Raebel MA, et al. Intensification of antihyperglycemic therapy among patients with incident diabetes: a Surveillance Prevention and Management of Diabetes Mellitus (SUPREME-DM) study. Pharmacoepidemiol Drug Saf. 2014;23(7):699-710.

36. Deyo RA, Cherkin DC, Ciol MA. Adapting a clinical comorbidity index for use with ICD-9-CM administrative databases. J Clin Epidemiol. 1992;45(6):613-619

37. Amendment: NIH Policy and Guidelines on the Inclusion of Women and Minorities as Subjects in Clinical Research - October, 2001. NOTICE: NOTOD-02-001 2001 [cited 2015 june 6]; Available from: http://grants.nih. gov/grants/guide/notice-files/not-od-02-001.html; accessed 7/22/15.

38. Nathan DM, et al. Medical management of hyperglycemia in type 2 diabetes: a consensus algorithm for the initiation and adjustment of therapy: a consensus statement of the American Diabetes Association and the European Association for the Study of Diabetes. Diabetes Care. 2009;32(1):193-203.

39. Hicks LS, et al. Determinants of racial/ethnic differences in blood pressure management among hypertensive patients. BMC Cardiovasc Disord. 2005;5(1): 16 .

40. Bullock KC, et al. Race as a factor for intensification of diabetes medications. Diabetes Educ. 2013;39(3):335-343.

41. Bolen SD, et al. Factors associated with intensification of oral diabetes medications in primary care provider-patient dyads: a cohort study. Diabetes Care. 2009;32(1):25-31

42. Lafata JE, et al. Sustained hyperglycemia among patients with diabetes: what matters when action is needed? Diabetes Care. 2009;32(8): 1447-1452.

43. Virani SS, et al. Frequency and correlates of treatment intensification for elevated cholesterol levels in patients with cardiovascular disease. Am Heart J. 2011;162(4):725-732 e1.

44. Schmittdiel JA, et al. Why don't diabetes patients achieve recommended risk factor targets? Poor adherence versus lack of treatment intensification. J Gen Intern Med. 2008;23(5):588-594.

45. Osterberg L, Blaschke T. Adherence to medication. N Engl J Med. 2005;353(5):487-497.
46. Gazmararian JA, et al. Factors associated with medication refill adherence in cardiovascular-related diseases: a focus on health literacy. J Gen Intern Med. 2006;21(12):1215-1221.

47. Chapman RH, et al. Predictors of adherence with antihypertensive and lipid-lowering therapy. Arch Intern Med. 2005;165(10): 1147-1152.

48. Rodondi $\mathbf{N}$, et al. Therapy modifications in response to poorly controlled hypertension, dyslipidemia, and diabetes mellitus. Ann Intern Med. 2006; 144(7):475-484.

49. Chaudhry SI, Berlowitz DR, Concato J. Do age and comorbidity affect intensity of pharmacological therapy for poorly controlled diabetes mellitus? J Am Geriatr Soc. 2005;53(7): 1214-1216.

50. Harle CA, Harman JS, Yang S. Physician and patient characteristics associated with clinical inertia in blood pressure control. J Clin Hypertens (Greenwich). 2013;15(11):820-824.

51. Karter AJ, et al. Achieving good glycemic control: initiation of new antihyperglycemic therapies in patients with type 2 diabetes from the Kaiser Permanente Northern California Diabetes Registry. Am J Manag Care. 2005; 11(4):262-270.

52. Karter AJ, et al. Glycemic response to newly initiated diabetes therapies. Am J Manag Care. 2007;13(11):598-606.

53. Saffar D, et al. Racial disparities in lipid control in patients with diabetes. Am J Manag Care. 2012;18(6):303-311.

54. Voorham $\mathbf{J}$, et al. Identifying targets to improve treatment in type 2 diabetes; the Groningen Initiative to aNalyse Type 2 diabetes Treatment (GIANTT) observational study. Pharmacoepidemiol Drug Saf. 2010;19(10): 1078-1086.

55. Gregg EW, et al. Changes in diabetes-related complications in the United States, 1990-2010. N Engl J Med. 2014;370(16):1514-1523.

56. American Diabetes Association. Strategies for improving care. Diabetes Care. 2015;38(Supplement 1):S5-S7.

57. Beal AC. Health policy brief: achieving equity in health. Health Aff. 2011;30(10) 1868-1871. http://content.healthaffairs.org/content/30/10/ 1868.full\#aff-1; accessed 10/6/11.

58. Warnecke RB, et al. Approaching health disparities from a population perspective: the National Institutes of Health Centers for Population Health and Health Disparities. Am J Public Health. 2008;98(9):1608-1615.

59. Raebel MA, et al. Importance of including early nonadherence in estimations of medication adherence. Ann Pharmacother. 2011;45(9): 1053-1060.

60. Raebel MA, et al. Characteristics of patients with primary non-adherence to medications for hypertension, diabetes, and lipid disorders. J Gen Intern Med. 2012;27(1):57-64.

61. Herman WH, et al. Racial and ethnic differences in hemoglobin Alc among patients with impaired glucose tolerance in the diabetes prevention program. Diabetes Care. 2007;30(10):2453-7. 